\title{
Thermal influence of neighbouring GSHP installations: relevance of heat load temporal resolution
}

Maria Letizia Fascì Alberto Lazzarotto

\author{
J osé Acuña
}

J oachim Claesson

\begin{abstract}
In densely populated areas where many ground source heat pump (GSHP) systems are present, it becomes important to consider the thermal influence of neighbouring GSHP installations while designing these systems. This question has started to become frequent in cities like Stockholm in Sweden. For the design and performance analyses of the GSHP systems, simulations at different detail levels regarding time step are used. Borehole heat loads of real installations can be estimated with different time resolution from case to case. This article presents a first step towards the development of a model to calculate the mutual influence of neighbouring GSHP installations: a first elementary model is developed to quantify such influence, then the error introduced when performing simulations with different heat load steps, i.e. annual and hourly, is analyzed from a perspective of multiple neighbouring GSHP installations. It is found that a negligible error is derived when considering low temporal resolution data.
\end{abstract}

\section{NTRODUCTION}

Ground source heat pumps (GSHPs) are systems that can extract/reject heat from/to the underground to provide domestic heating/cooling and hot water. The extraction can occur in several ways, the most common way is using borehole heat exchangers (BHEs): vertical pipe loops buried in the ground through which a fluid is circulated (Lund and Boyd, 2016). GSHPs became popular in western countries after the oil crisis of the "70s thanks to their higher energy efficiency compared to boilers, most commonly used solution to provide heat at that time. The number of installed GSHP systems has increased since then (Sanner, 2016).

In Sweden around one fifth of the single-family buildings use a GSHP; most of them are single-family houses using the systems for heating and hot water (Gehlin and Andersson, 2016). Using the GSHP for heat extraction only leads to a successive depletion of the heat surrounding the borehole that can decrease the system performance and eventually influence the surrounding installations. The decrease of a system performance due to its own operation is already taken into account during the design phase of the system, but the effects on surrounding systems are not considered nowadays. This induced the Swedish authorities to set up rules to avoid thermal interaction among neighbouring systems. The general rule for single-family buildings recommends $20 \mathrm{~m}$ as minimum distance between 2 boreholes on neighbouring properties (SGU, 2016). Such distance may be enough to guarantee that two neighbouring BHEs do not influence each other significantly during the first 15 years of operation. For example, for a typical heat extraction BHE (see table 1) it was calculated that the temperature variation at $20 \mathrm{~m}$ from the borehole, after 15 years of operation, is around $0.3{ }^{\circ} \mathrm{C}$, while the temperature variation at $0.1 \mathrm{~m}$ from the borehole is $3.2^{\circ} \mathrm{C}$. This means that the influence of a borehole on an identical neighbouring borehole distant $20 \mathrm{~m}$ is around $10 \%$ of the influence of the boreholes on itself.

Though the influence of a single borehole can be negligible at greater distances than $20 \mathrm{~m}$, in dense ground source heat pump areas (DGSHPAs), here referred to as areas where several independent GSHPs are installed, their influences add up and may result in a non-negligible effect. Another factor that should be taken into account is that, although the lifetime of a heat pump is around 20 years, the lifetime of the borehole can be longer; there are areas in Stockholm were boreholes and heat pumps have been operating for more than 30 years already (SKVP 2017). Extending the operation

Maria Letizia Fascì (mlfasci@kth.se) is a PhD student, Alberto Lazzarotto and José Acuña are researchers, and Joachim Claesson is docent at Royal Institute of Technology (KTH). 
time of a borehole where only heat extraction occurs means extending its radius of influence and the intensity of its influence: the temperature variation at $20 \mathrm{~m}$ due to the borehole of the previous example increases to around $0.4^{\circ} \mathrm{C}$ after 30 years and around $0.5^{\circ} \mathrm{C}$ after 100 years.

Table 1. Example of borehole and ground characteristics for a Swedish villa

\begin{tabular}{|c|c|c|c|c|c|}
\hline \multicolumn{2}{|c|}{ Borehole properties } & \multicolumn{5}{c|}{ Ground properties } \\
\hline $\begin{array}{c}\text { Total annual borehole heat } \\
\text { load }\left(\mathbf{H L}_{\mathrm{b}, \mathrm{a}}\right)[\mathrm{kWh} / \text { year }]\end{array}$ & $\begin{array}{c}\text { Length } \\
{[\mathrm{m}]}\end{array}$ & $\begin{array}{c}\text { Conductivity } \\
{[\mathrm{W} / \mathrm{m} / \mathrm{K}]}\end{array}$ & $\begin{array}{c}\text { Density } \\
{\left[\mathrm{kg} / \mathrm{m}^{\wedge} 3\right]}\end{array}$ & $\begin{array}{c}\text { Specific heat } \\
{[\mathrm{J} / \mathrm{kg} / \mathrm{K}]}\end{array}$ & $\begin{array}{c}\text { Undisturbed } \\
\text { temperature }\left[{ }^{\circ} \mathrm{C}\right]\end{array}$ \\
\hline 10000 & 100 & 3,1 & 2300 & 870 & 8 \\
\hline
\end{tabular}

Currently, several models, both commercial and developed by researchers, are available for estimating the temperature evolution at the borehole wall in a BHE field; a summary of the models is given by Yang, et al. (2010). However, the authors of this paper are aware of only one recent model specifically designed to take into account the presence of neighbouring GSHP installations and so to model DGSHPAs; the model is based on the infinite line source (Witte, 2018). It is therefore the goal of the authors to develop a complete model for DGSHPAs. The main difference between the dedicated models for BHE fields and the model that the authors want to develop is that, in the latter, the borehole operating conditions (i.e. secondary fluid temperature and flow rate) are independent. Therefore the designer of an individual borehole in a DGSHPA has little information about the operating conditions of the surrounding boreholes. Thus, the new model, in addition to solving the heat transfer problem, has to estimate the uncertainty on the solution due to the uncertainties on the input data: boreholes positions, loads, and ground thermal properties, among others.

Among the input data, the BHEs' loads is the most difficult information to accurately assess without a direct interaction with all the house owners. For the sake of use, the model should be able to provide this values given easily accessible information. Building loads, and consequently also BHE loads vary from year to year and are not constant throughout the year, but vary over the seasons and the hours of the day. The difficulty in estimating the heat load increases as the heat load resolution increases. It is easier to estimate the loads with yearly resolution. Besides, using coarser time resolutions decreases the computational time of the model. Several studies are available about the importance of the heat load resolution and the possibility to use aggregated loads to estimate the borehole wall temperature in borehole fields (Yavuzturk and Spitler, 1999, Bernier et al, 2004, Marcotte and Pasquier, 2008, Claesson and Javed, 2012). They show that it is important to know the recent BHE history with hourly resolution, but it is possible to aggregate the least recent history. Although it is known that the further from the borehole the coarser the load time resolution can be without significantly compromising the accuracy of the results, no study focused on quantifying the accuracy of annual load aggregation for distances higher than $20 \mathrm{~m}$ has been found.

This paper represents a first step towards the development of the aforementioned model. The work consisted in two parts: in the first part an elementary model to calculate thermal influence in densely populated areas was developed. The model was used to estimate the possible influence between boreholes in Stockholm. The second part consisted in the evaluation of the error in case of load aggregation for long distances $(>20 \mathrm{~m})$. The error was calculated for individual boreholes and DGSHPAs.

\section{METHODOLOGY}

\section{Thermal influence in densely populated areas}

The first part of the study consisted in calculating the thermal influence of neighbouring GSHP systems on a central borehole (CB) in a DGSHPA. Two borehole grids characterized by a minimum distance among the BHEs where considered: a square grid and a triangular grid. The triangular configuration is the one that maximizes the number of neighbouring boreholes within a certain radius and minimizes the borehole-to-borehole distances. Figure 1 shows an 
example of the two possible configurations described.
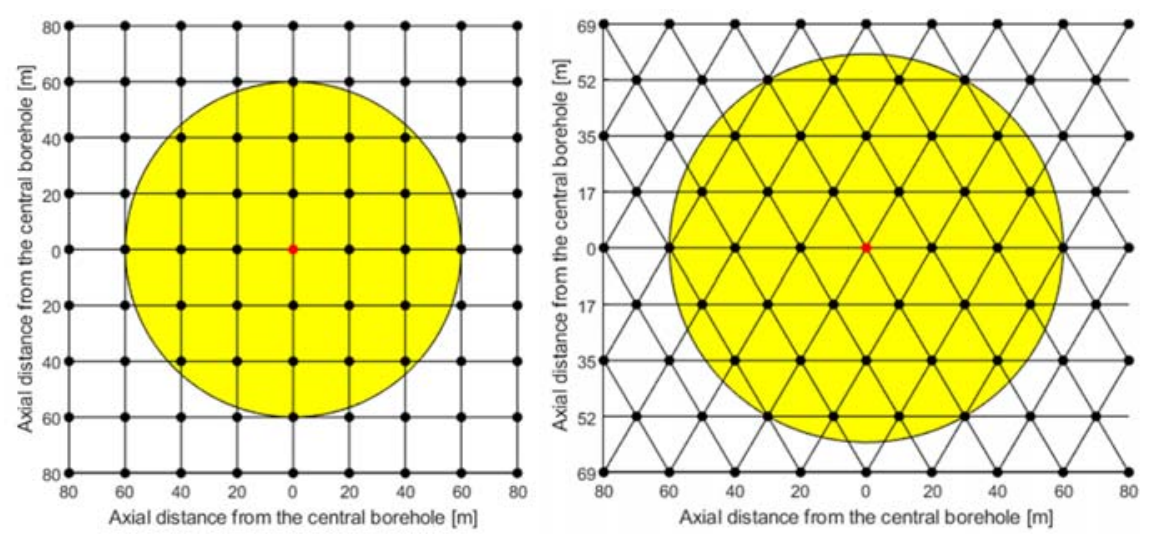

Figure 1 Borehole configurations: in each configuration the red dot is the influenced borehole, the black dots are the neighbouring boreholes. The boreholes in the yellow area are the ones influencing the central borehole after a certain period of operation.

All the boreholes in the grids were assumed to be equally deep and have the same annual heat load and profile. The region of influence, i.e. the region containing the BHEs influencing the central BHE was found iteratively: an initial radius of influence (RI) was set equal to $20 \mathrm{~m}$, minimum distance among the boreholes. The number of BHE within the RI and their distances from the central borehole were calculated. The thermal response due to each single BHE after 100 years of operation at constant load was calculated. The results for all the boreholes were then superimposed; thus the thermal response due to all the surrounding BHEs was calculated. This was repeated for increasing radii of influence until the difference in the thermal response for two consecutive RIs was lower than $0.001{ }^{\circ} \mathrm{C}$.

To calculate the thermal response due to each single borehole, the boreholes were considered as continuous line heat sources with uniform and constant heat flux in a semi-infinite, uniform, isotropic media with constant properties. The validity of the uniform heat flux assumption for the distances considered must be further investigated, as it might lead to an over- or underestimation of the boreholes influence. The validity of the constant heat flux assumption is showed later in this article. The boreholes and ground characteristics are described in table 1 . The temperature evolution was then calculated using the finite line source model (Spitler and Bernier, 2016); the formulation given by Lamarche and Beauchamp (2007) was used for the calculation of the ground thermal response $\mathrm{g}$.

For both configurations the thermal responses due to the boreholes within certain radii were calculated. The radius of influence after given operation times, the number of influencing boreholes and their effect on the central borehole are shown in the results section.

\section{Errors due to load averaging}

The second part of the study consisted in estimating the error on the thermal response calculation when the heat load time resolution used for the calculation was coarser than a reference calculation with a finer time heat load resolution. This was done for single boreholes first and then for DGSHPAs. To do so the temperature response due to a known hourly heat load (finest resolution) was calculated and compared with the results obtained using annual averaged heat loads.

To create an hourly load profile over a year, the total annual building heat load was divided into space heating and hot water loads. The values given by the Swedish Energy Agency for an average Swedish villa were used as reference, both for the total annual building heat load and the ratio between heating and hot water demand (Energimyndigheten 2017); the values used are shown in table 2.

The heating load was considered dependent on the ambient temperature. The ambient temperature considered was the one given for Stockholm by the Swedish meteorological and hydrogeological institute (SMHI 2017). Several 
hourly profiles were created: for year 2010 to 2016 . A base temperature of $15.5^{\circ} \mathrm{C}$ was taken; the houses need mechanical heating when the ambient temperature falls below the base temperature (EEA, 2017). The heating load was considered 0 during the hours when the ambient temperature was higher than the base temperature, calculated as follows otherwise:

$$
H L_{h, j}=H L_{h, a} \cdot \frac{T_{b a s e}-T_{a m b, j}}{\sum_{j=1}^{8760} T_{\text {base }}-T_{a m b, j}}
$$

where the sum at the denominator of the formula only considers the positive differences between the base and ambient temperatures. The hot water profile was considered the same for every day of the year, the hourly profile over the day was chosen among the ones in the literature (Ulseth, et al. 2017). The hourly loads were then calculated for every hour of the year as the sum of heating and hot water hourly loads. The total annual heat load was assumed constant from year to year and the load profile being the same every year. The temperature trend along the influenced borehole wall was calculated for 100 years of operation.

Table 2. Heat loads for a typical Swedish villa

\begin{tabular}{|c|c|c|}
\hline $\begin{array}{c}\text { Total annual building } \\
\text { heat load }\left(\mathrm{HL}_{\mathrm{h}, \mathrm{a}}\right)[\mathrm{kWh}]\end{array}$ & $\begin{array}{c}\text { Heating load } \\
{[\% \text { of the total load }]}\end{array}$ & $\begin{array}{c}\text { Hot water load } \\
{[\% \text { of the total load }]}\end{array}$ \\
\hline 15000 & 86 & 14 \\
\hline
\end{tabular}

The borehole load was calculated from the house load assuming that the COP of the HP was constant and equal to 3 (Energimyndigheten 2017); it was calculated as follows:

$$
H L_{b}=H L_{h} \frac{C O P-1}{C O P}
$$

The thermal response from constant heat load was calculated as described in the previous section. The superposition method (Spitler and Bernier, 2016), without load aggregation, was used to calculate the response from non-constant heat loads:

$$
T_{b}\left(t_{n}\right)-T_{0}=\sum_{i=1}^{n} \frac{q_{i}-q_{i-1}}{2 \pi k} g\left(t_{n}-t_{i}, H, d, \alpha\right)
$$

Several borehole distances and lengths were considered. The results obtained using the hourly profile were compared with the ones obtained with yearly profiles.

The borehole grids described in the previous paragraph were then considered. The results obtained for single boreholes suggested that the error is not strongly dependent on the boreholes length (figure 5), therefore only grids of $100 \mathrm{~m}$ long boreholes were considered for DGSHPAs. The thermal response on the central borehole was calculated considering both yearly and hourly resolution heat loads in the surrounding boreholes. The errors associated to coarse load resolutions were calculated as previously done for individual boreholes.

\section{RESULTS AND DI SCUSSION Thermal influence in densely populated areas}


The radii of influence after 15, 30, 50 and 100 years of operation were calculated as discussed in the methodology section. The boreholes and ground properties are shown in table 1. The results are shown in table 3. It should be considered that table 3 shows the results of the algorithm discussed in the methodology and not empirical results.

Table 3. Influencing radii for several operational times.

\begin{tabular}{|c|cccc|}
\hline Years of operation & 15 & 30 & 50 & 100 \\
\hline Radius of influence [m] & 140 & 180 & 220 & 300 \\
\hline
\end{tabular}

Figure 2 shows that considering an RI of 80,100 or $300 \mathrm{~m}$ after 15 years of operation does not lead to any significant difference in the results; while table 3 shows that the RI suggested by the algorithm used is $140 \mathrm{~m}$. The algorithm used is then very conservative and can be improved so to decrease the computational time of the simulation without losing significantly in accuracy.

The number of boreholes within certain radii is shown below for the square and triangular grids.

Table 4. Number of boreholes in square and triangular grid

\begin{tabular}{|l|ccccccccc|l|}
\hline Radius [m] & 20 & 40 & 60 & 80 & 100 & 150 & 200 & 250 & 300 & \\
\hline $\begin{array}{l}\text { Boreholes } \\
\text { within the } \\
\text { radius }\end{array}$ & 4 & 12 & 28 & 48 & 80 & 176 & 316 & 488 & 708 & Square grid \\
\cline { 2 - 9 } & 6 & 18 & 36 & 60 & 90 & 198 & 366 & 570 & 720 & $\begin{array}{l}\text { Triangular } \\
\text { grid }\end{array}$ \\
\hline
\end{tabular}

The thermal responses of the central borehole of square and triangular grids were calculated over 100 years of operation. The responses accounting for all influencing boreholes within certain radii are shown below.
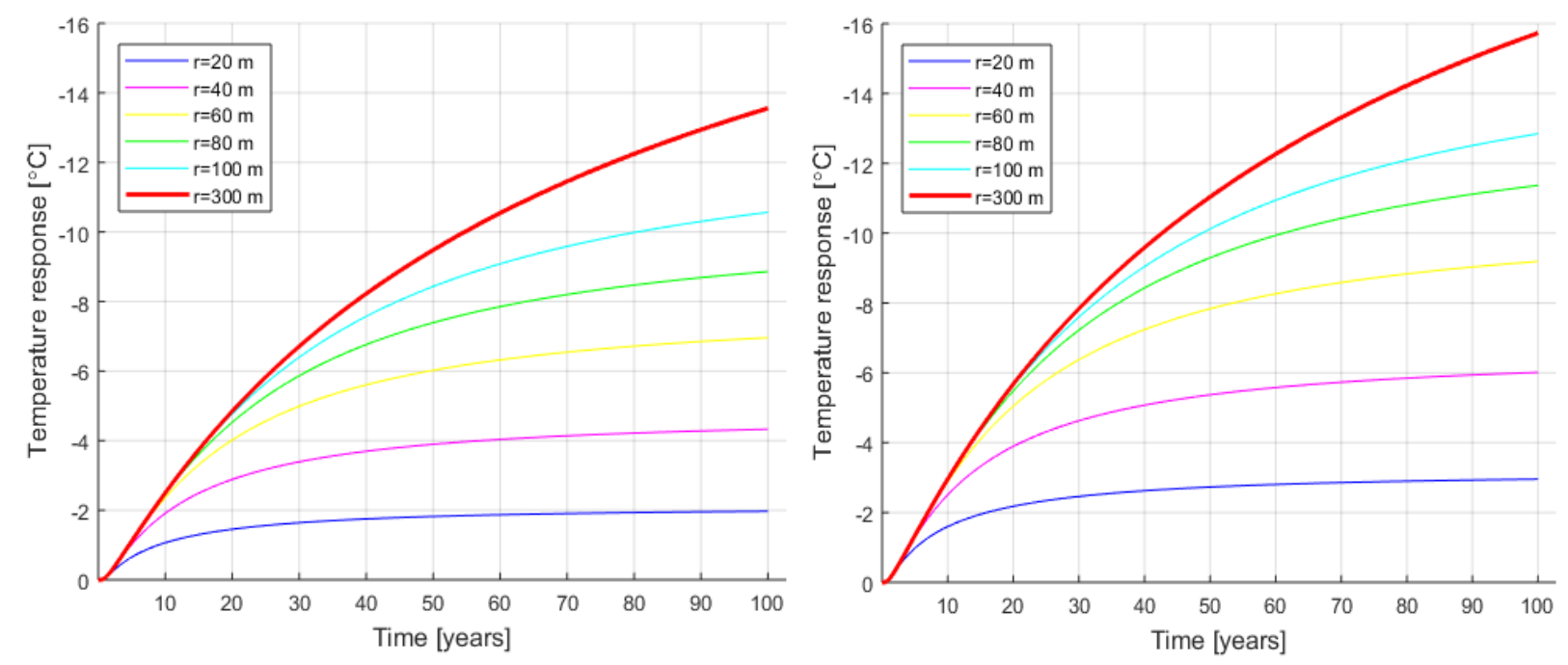

Figure 2 Thermal response of the central borehole of a square grid (left) and triangular grid (right).

As expected, in case of triangular grid the temperature response is more significant; in particular, after 100 years of operation the temperature decrease in a square grid is $14^{\circ} \mathrm{C}$, in a triangular one it is $16^{\circ} \mathrm{C}$. Figure 2 also shows that already after 15 years of operation the thermal response of the central borehole is around $4{ }^{\circ} \mathrm{C}$, therefore not negligible.

It is clear that under the conditions considered in this study, the exploitation of the underground heat cannot be considered sustainable. These results are however insufficient for strong conclusions as many phenomena occurring in the ground were not considered: heat conduction was the only heat transfer type considered, the ground properties 
were not considered temperature dependent, and the surface boundary condition set was uniform with constant temperature equal to the initial underground temperature. Besides phase change was not taken into account; considering it could change the results as the undisturbed ground temperature in Stockholm is around $8{ }^{\circ} \mathrm{C}$, lower than the calculated temperature decrease. However ground freezing is not recommended, therefore rather than creating a model able to account it, the neighbouring systems should be designed to avoid it.

\section{Errors due to load averaging}

In the calculation of the error due to load approximation, the results obtained do not differ significantly depending on the hourly profile considered. The results obtained with the hourly profile for year 2011 are shown, as the errors obtained using this profile are slightly higher than in all the other cases and therefore lead to the most conservative conclusions.

Figure 3 shows on the left the thermal influence of a $100 \mathrm{~m}$-deep borehole at $20 \mathrm{~m}$ distance. The annual heat load on the borehole is $10 \mathrm{MWh}$. The results obtained using both hourly and yearly resolution are shown. The two curves match very well. The absolute difference between them is shown in the graph on the right.
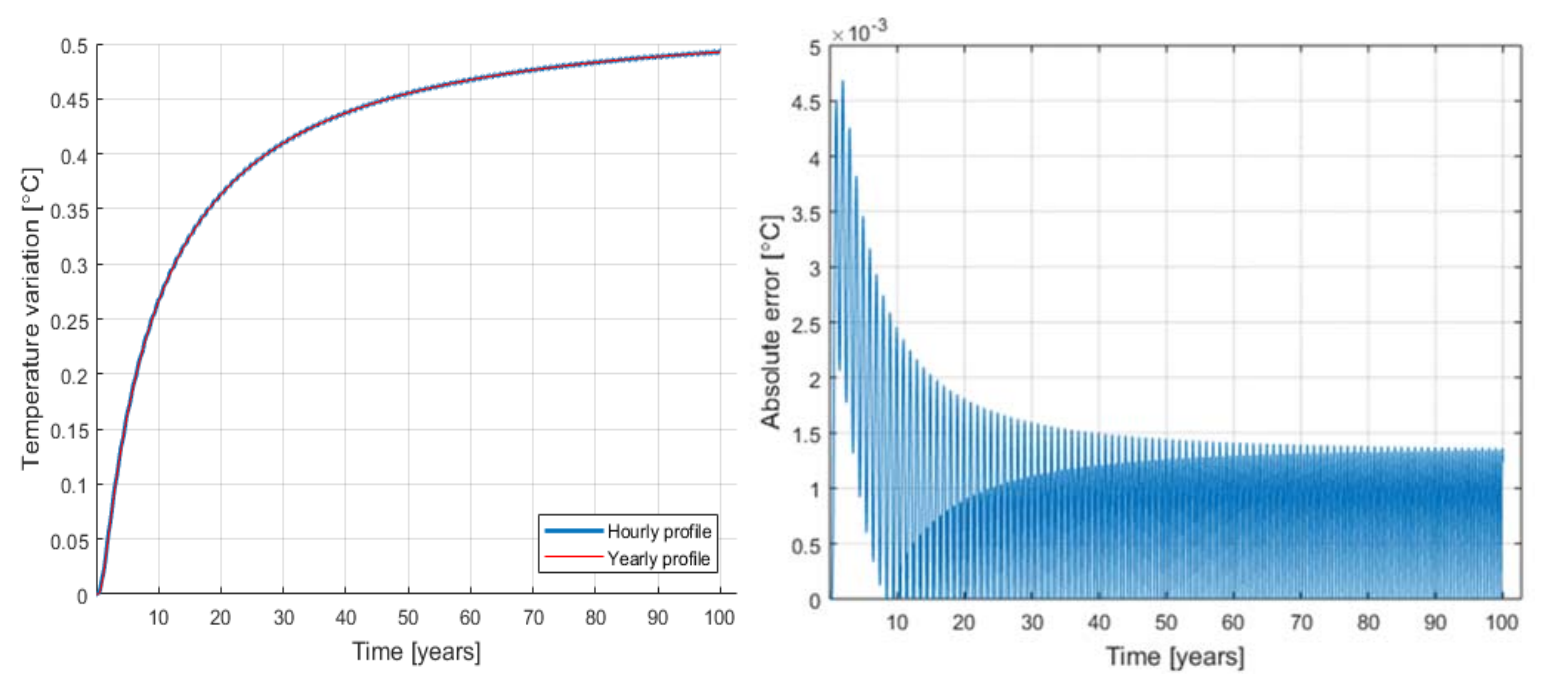

Figure 3 Temperature influence of neighbouring borehole obtained with hourly and yearly load resolution (left). Absolute difference between the results obtained with hourly and yearly resolution (right).

The maximum error, in case of yearly load resolution, is reached during the first years of operation and decreases logarithmically until reaching a steady state. For the case considered the steady state error is lower than $0.0015{ }^{\circ} \mathrm{C}$.

In figure 4, the maximum error obtained due to the load resolution is shown for several borehole depths and distances. The total heat load on the borehole is the same for all the cases, so the heat load per borehole length differs from case to case. The graph shows that the error made decreases for longer distances and increasing borehole depth. Using yearly load resolution leads to unacceptable errors for short borehole-to-borehole distances $(<5 \mathrm{~m})$, but the authors feels confident in stating that the errors made for distances over $20 \mathrm{~m}$ are acceptable $\left(<0.01{ }^{\circ} \mathrm{C}\right)$. Similarly to figure 4, figure 5 shows the maximum error obtained due to the load resolution for several borehole depths and distances, the difference with figure 4 is that it is the heat load per unit length of borehole to be the same for all the boreholes and not the total borehole heat load. The figure shows that for a fixed specific linear heat load the influence of the borehole length on the error is lower, though it can be observed that slightly higher errors are made for longer boreholes. In particular the curve for a $50 \mathrm{~m}$ long borehole differs significantly for longer distances. The explanation suggested by the authors is that the mitigative effect of the heat exchange in the axial direction is lower for longer boreholes, so is the attenuation of the fluctuating response due to fluctuating loads. 


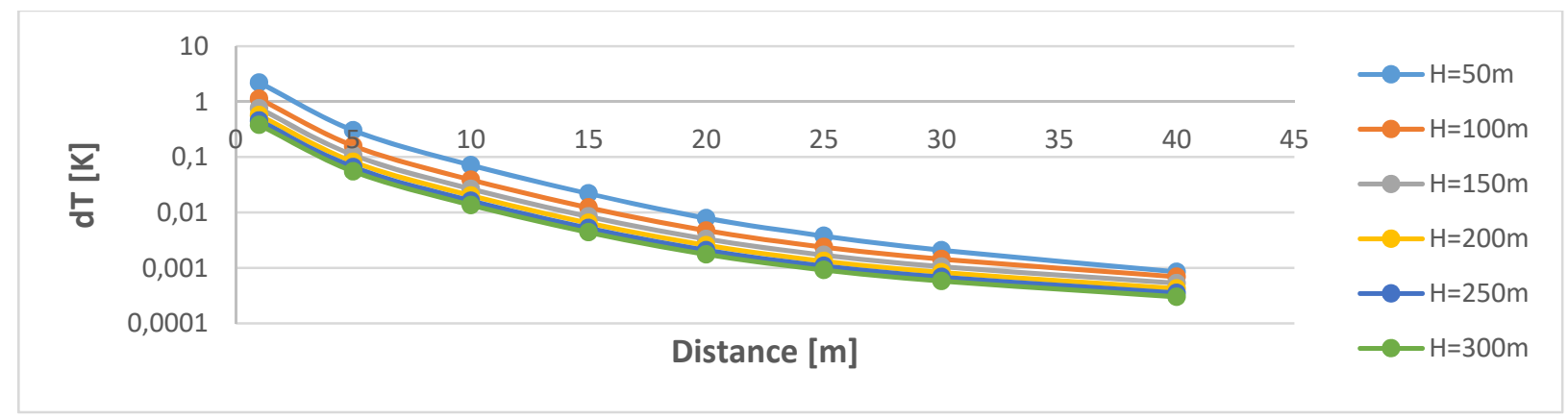

Figure 4 Maximum absolute errors made using yearly load resolution. Annual borehole heat load $=10000 \mathrm{kWh}$.

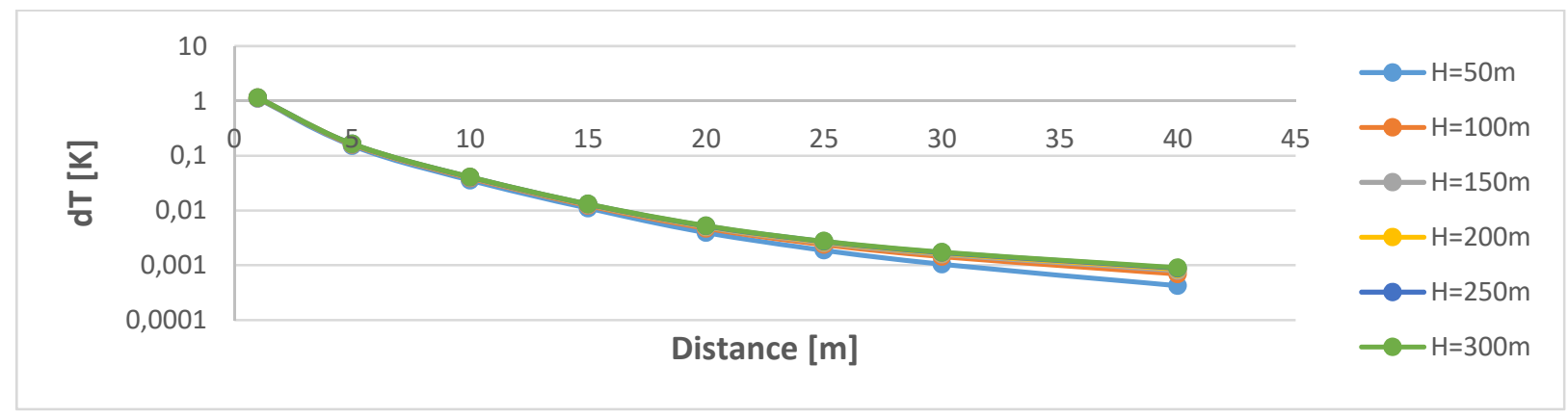

Figure 5 Maximum absolute errors committed using yearly load resolution. Annual borehole heat load per unit length = $100 \mathrm{kWh} / \mathrm{m}$.

The errors obtained for the whole DGSHPAs are finally shown in figure 6.
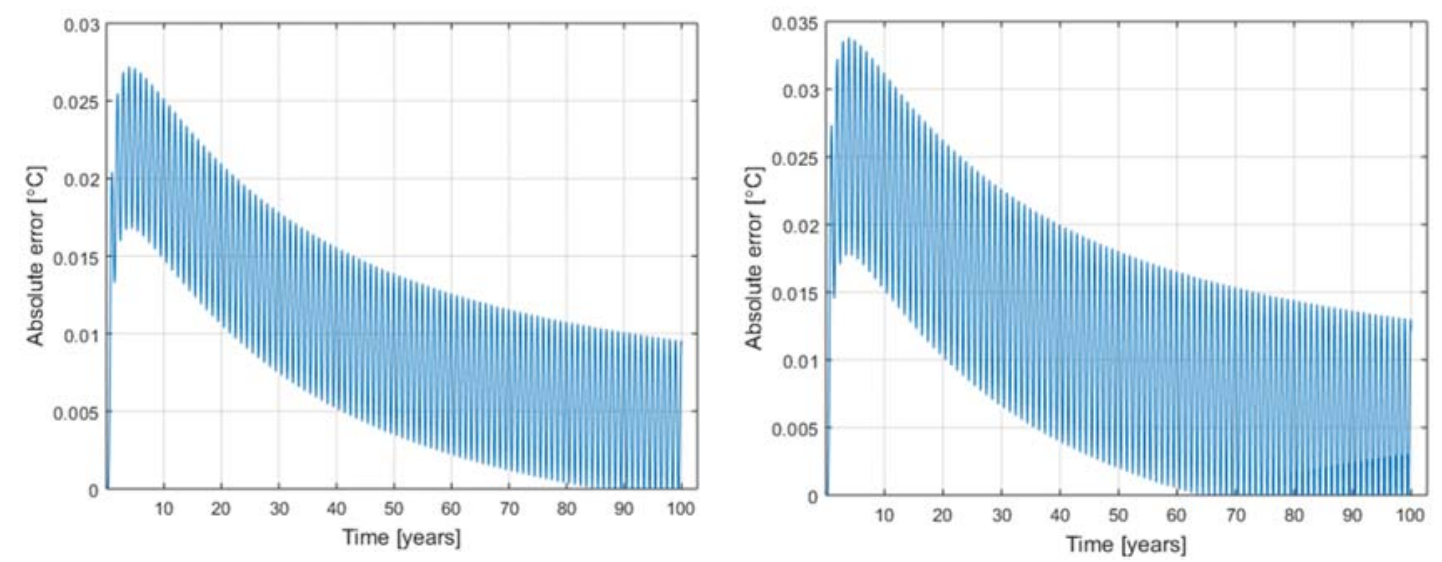

Figure 6 Absolute difference between the results obtained with hourly and yearly resolution for the square grid (left) and the triangular grid (right).

For both configurations the error is always lower than $0.035^{\circ} \mathrm{C}$. It is noteworthy that the load approximation error for a borehole field is not the mere sum of the errors of the individual boreholes, but is lower due to the different time-shift of the thermal responses at different distances from the heat source. Therefore using yearly load resolution is considered an acceptable approximation by the authors. 


\section{CONCLUSIONS}

The results showed that measures need to be taken to prevent strong thermal interference between boreholes in densely populated areas. A tool that allows an accurate estimation of the boreholes thermal interaction is necessary to be able to forecast the evolution of ground temperature. The tool should be able to forecast the thermal behaviour of the ground where several boreholes, in arbitrary configurations and subject to different loads, are operating. The tool could be also useful to determine guidelines for how systems in densely populated areas should be designed.

One step has been taken towards the development of such a model by evaluating the importance of borehole load resolution for distant neighbouring boreholes $(>20 \mathrm{~m})$. It has been concluded that having yearly averaged loads leads to an acceptable accuracy of the results.

The next step towards the development of the model is to add the possibility to set not uniform temperature at the top surface. In particular the surface temperature is influenced by the presence of buildings and asphalt, therefore is on average higher than the undisturbed ground temperature. With such condition the resulting ground temperature response would be mitigated.

\section{ACKNOWLEDGMENTS}

This work was supported by the Swedish Energy Agency.

\section{NOMENCLATURE}

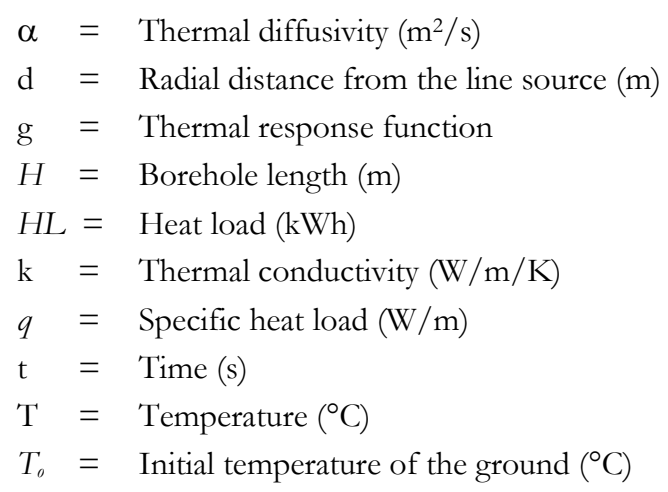

\section{Subscripts}

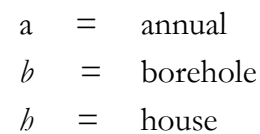

\section{REFERENCES}

Bernier, M.A., P. Pinel, R. Labib, R. Paillot, 2004. A Multiple Load Aggregation Algorithm for Annual Hourly Simulations of GCHP Systems. HVAC\&R Research 10, 471-487.

Claesson, J., S. Javed, 2012. A load-aggregation method to calculate extraction temperatures of borehole beat exchangers.

ASHRAE Transactions 118, 530-539.

Energimyndigheten, 2017. Berguärmepumpar- mätningar i hus. Available online at: http://www.energimyndigheten.se/tester/tester-a-o/bergvarmepumpar/bergvarmepumpar---matningar-ihus/ 
European Environment Agency, 2017. Heating and cooling degree days. Available online at: https://www.eea.europa.eu/data-and-maps/indicators/heating-degree-days/assessment

Gehlin, S., O. Andersson, 2016. Geothermal Energy Use, Country Update for Sweden. Proceeding of European Geothermal Congress 2016, Strasbourg, France, September 19-24th 2016.

Lamarche, L. and B. Beauchamp. 2007. A new contribution to the finite line-source model for geothermal boreholes. Energy and Buildings 39: 188-198.

Lund, J.W., T.L. Boyd, 2016. Direct utilization of geothermal energy 2015 worldwide review. Geothermics 60: 66-93.

Marcotte, D., P. Pasquier, 2008. Fast fluid and ground temperature computation for geothermal ground-loop heat exchanger systems. Geothermics 37: 651-665.

Sanner, B., 2016. Shallow geothermal energy-history, development, current status, and future prospects. European Geothermal Congress. Strasbourg, France: 19-24.

Spitler, J.D. and M. Bernier. 2016. Vertical borehole ground heat exchanger design methods. In: S.J. Rees Advances in Ground-Source Heat Pump Systems. London: Woodhead Publishing.

Svenska kyl och värmepump föreningen, 2017. Värmepumpförsäljning. Available online at: https://skvp.se/aktuellto-opinion/statistik/varmepumpsforsaljning

Sveriges geologiska undersökning, 2016. Vägledning för att borra brunn. Available online at: https:// resource.sgu.se/produkter/broschyrer/vagledning-normbrunn-16.pdf

Swedish Meteorological and Hydrogeological Institute, 2017. Meteoralogiska observationer. Available online at: https://opendata-download-metobs.smhi.se/explore/?parameter=0\#

Ulseth, R., K.B. Lindberg, L. Georges, M.J. Alonso, Å. Utne, 2016. Measured load profiles and heat use for "low energy buildings" with heat supply from district heating. 15th International Symposium on District Heating and Cooling. Seoul, South Korea: 180-190.

Witte, H.J.L., 2018: A Novel Tool for Assessing Negative Temperature Interactions between Neighbouring Borehole Heat Exchanger Systems. 14th international conference on energy storafge, April 2018, Adana Turkey.

Yang, H., P. Cui, Z. Fang, 2010. Vertical-borehole ground-coupled heat pumps: A review of models and systems. Applied Energy 87: 16-27.

Yazuzturk, C., J.D. Spitler, 1999. A short time step response factor model for vertical ground loop heat exchangers. Ashrae Transactions $105,475$. 